\title{
Aviation Human Error Modelled as a Production Process
}

\author{
Dirk Pons ${ }^{*}, 1$ and Karla Dey ${ }^{2}$ \\ ${ }^{I}$ Department of Mechanical Engineering, University of Canterbury, Private Bag 4800, Christchurch 8020, New Zealand \\ ${ }^{2}$ Department of Mechanical Engineering, University of Canterbury, New Zealand
}

\begin{abstract}
As technology systems have become more complex, so it is increasingly difficult for human operators to comprehend how the system is behaving. There is a need to better understand the causes of human-error in the context of the situational variables. The specific case under examination is the process of landing an aircraft. This paper applies a production engineering perspective. By production-process, we refer to the set of actions that are necessary to move a system from one state to a desired new state. Such processes involve mechanisms for taking inputs and converting them to the desired outputs, under certain controls and constraints. Human error is thus treated as a constraint on the processes. A novel process methodology is developed to represent how technical systems, situational variables, external factors, and human error evolve over time in a process. The applicability is demonstrated with a dataset of case studies. In parallel, a new categorization of human errors is derived for this situation. The method permits cases to be examined individually, and also collectively for patterns. The results show that the initial landing approach is often the point of error initiation. For the specific case of landing accidents the methodology identifies that the failure causality was the lack of attention to establish procedure at the very start of descent, followed by persistent disregard of disconfirmatory evidence at the initial landing approach, especially under conditions of poor visibility. The paper makes a methodological contribution as well as suggesting new insights for how human error occurs at landing.
\end{abstract}

Keywords: Aircraft pilot, production process, safety, sociotechnical interaction, systems engineering.

\section{HIGHLIGHTS}

- A production engineering perspective is applied to aviation.

- Methodology represents evolution of sociotechnical errors.

- Application to small dataset of cases for landing accidents.

- $\quad$ Pilots show persistent disregard of disconfirmatory evidence.

\section{INTRODUCTION}

Complex technical systems can fail due to failure of a technology component, or operator error, or can be driven to failure by organisational factors. Mechanisms to anticipate the technology failure are the best developed. However, anticipating the contribution of human error to the overall reliability of a given technical system is not straightforward, since it can be difficult to trace the sequence of causality from human error through system failure. Consequently prophylactic risk assessment has significant limitations in the area of human reliability analysis and organisational factors.

Furthermore, there is an agent perspective to consider in that Human operators are functionally embedded within

Address correspondence to this author at the Department of Mechanical Engineering, University of Canterbury, Private Bag 4800, Christchurch 8020, New Zealand; Tel: +64 3364 2987, Ext. 7214;

E-mail: dirk.pons@canterbury.ac.nz technical systems as operators and supervisory decision-makers. They are agents in that they have a causal contribution to the state taken by the technical system. Moreover they have to make their decisions under time pressure, and also dynamically since the system changes state. Unexpected emergency responses may be required from human operators, and such situations are cognitively demanding and of greater risk of error. As technology systems have become more complex, so it has become increasingly difficult for human operators to comprehend how the system is behaving. There can be many reasons for this: large volumes of data presented by the system can overwhelm the operator; the system may be sufficiently complex that the operator only has a partial mental model of its operation; the system may change its mechanics as it degrades and the supervisory control system may not detect the change. A further problem is the difficulty of adequately explaining how human error is determined by the group dynamics, organisational culture, psychology factors, and individual cognition.

This paper applies a production perspective to human error, whereby failure is conceptualised as a process that fails to achieve its intended outcome. We demonstrate this method by application to a small set of cases for flight accidents, with a particular focus on the landing phase.

\section{BACKGROUND LITERATURE}

\subsection{Risk Assessment Principles}

The process of risk analysis has been well established, and even specified in standards [1]. The process is generally 
perceived to be a progression of sequential tasks, for example ISO31000 and AS/NZS 4360 describe a process where the main activities are to 'establish the context', 'identify risks', 'analyse risks', evaluate risks', and 'treat risks'. Collateral activities include 'communicate and consult' and 'monitor and review', which are further elaborated with text descriptions $[2,3]$. The method is able to accommodate human error and risks other than technological error. However, it is important to note that these risk management methodologies limit themselves primarily to the prophylactic component, and only weakly if at all address the other components such as diagnosis and emergency response.

\subsection{Human-Error Generally}

The primary mechanism to include the dimension of human error into failure analysis is human reliability analysis (HRA), as opposed to probabilistic risk assessment (PRA) which focuses on the quantification of likelihood for plant and equipment failures. The process involves identifying potential operator errors and quantifying the probabilities (or at least likelihoods) of those errors, and anticipating the consequence on the technical system. Potential errors, which are context specific, may be identified by task analysis [4] based on observation and discussion. Conventional fault trees and event trees, which are common in PRA, have a limited ability to accommodate operator behaviour [5]. The focus in HRA is typically on operator error, rather than organisational errors. The former is closely linked to failure of a physical system, and easier to quantify. As with PRA, HRA does not readily identify the organisational and management factors, nor are some cognitive effects such as emotional state of the operator typically identified. Sometimes performance shaping factors are used to link operator errors to other factors such as management and sitespecific conditions, but may be difficult to justify or implement robustly. Identifying human errors is therefore not straight-forward in the HRA process.

Human operators make errors when their behaviour deviates from the intended. Typical consequences of human error are physical injury, damage to plant and equipment, and poor workmanship (for the manufacturing setting). Human errors have been classified $[5,6]$ into:

- $\quad$ slips (operator performed an action she did not intend),

- lapses (operator forgot information or to perform an action that was intended),

- mistakes (operator decided what action to take, and performed it, but it was an inappropriate choice in the first place), including perseveration/fixation (persistent acceptance of a false belief), and

- violations (operator knew what procedure to follow, but did not).

The broader organisational setting is represented in Reason's 'Swiss Cheese' model of error causation. This assumes multiple barriers to error must fail (the holes in slices of cheese must line up) for failure to occur. The errors include those listed above, and the barriers may include organisational, supervision, preconditions and operator actions. This is the dominant paradigm for thinking about human error, and provides a good motivation for having multiple layers of defence against error. However it promotes the idea of independence between the barriers, and it therefore fails to provide insight into the interactions between barrier systems. The Swiss Cheese model is overly simplistic and may even be a defective construct when it comes to complex interactions within socio-technological systems.

The other important paradigm in human error is Rasmussens's distinction between 'automated skill-based behaviour, rule-based "know-how" and knowledge-based analysis' [7], i.e. that there are several cognitive paths by which decision making may occur, and different types of errors occur in each of them $[8,9]$.

\subsection{Human-Error in Aircraft}

Human-error is a factor in nearly $70 \%-80 \%$ of all civil aviation accidents and has been so since improvements to aircraft safety plateaued in the 1970's [10-12]. Much work has been done to determine factors which influence the occurrence of human errors leading to aviation accidents.

Pilot gender was implicated as a major contributing factor to pilot error rates however investigations found that this early trend was attributed to the recent rise in female pilot numbers and the disparity in average pilot age and experience between female and male pilots and there was otherwise no significant difference in pilot-error rates [13, 14]. On the other hand pilot age and experience were found to have a significant impact on the ratio of human error based accidents to total accidents with a decreasing trend with increasing experience [14]. Cultural differences have also been implicated as a possible source of pilot-error, particularly in cultures where a large power distance is prevalent in the cabin setting $[15,16]$. Data mining of 30,243 accident and incident aviation reports between $1995-2008$ provided by the National Transportation Safety Board (NSTB) determined that a situational outcome was more likely to be a crash than an incident when pilot error was combined with multiple other contributing factors [17]. For situations where pilot-error was combined with only one other contributing factor, the ratio of crash outcomes to incidents was highest when the second factor was weather [17].

Helmreich's 'Crew Resource Management' paradigm identifies the main human error contributions as failures of communication, decision making, and leadership [18, 19]. This has lead to numerous training programmes within the airlines. The emphasis is on building awareness of the group dynamics and of the crew as a whole, as opposed to captaincentric behaviour. The purpose is to result in effective coordination of actions, especially the avoidance and detection of errors in unusual situations. It includes organisational and national culture $[16,20]$. The paradigm is primarily focussed on the human-human interactions. It addresses what could be called the protagonist vs multipleantagonists situation. It only weakly, if at all, addresses the wider interactions between the protagonist vs multipleantagonists $v s$ technical-system. 
A common idea in the aviation research and practitioner literature is that lack of 'situational awareness' contributes to human error. However this term has many possible meanings, and is seldom defined when it is used. The term is sufficiently broad and applied so variably, as to make it an unreliable concept: in any one application the choice of what to include in 'situational awareness' is invariably entirely adhoc. We recommend application of a systems engineering perspective instead, which would define situational awareness as perception of and response to the environment external to the protagonist. In that case it is understandable that it may include any of the following: detection of objects in the visual field, development of a mental model (or mental picture) for the dynamics of how the external system is behaving, working memory, reassessment of the external situation, openness to reassessment of mental models, projections of how the system is expected to evolve over time (anticipating system behaviour), keeping track of how the system has evolved, effective communication interactions with others, sharing of knowledge and development of a robust collective understanding of how the system is behaving, collective decision-making, awareness of the actions taken by other agents and coordination of such actions between team members, and leadership of the team. The above is a systems engineering reinterpretation of situational awareness, and is not how the literature usually portrays it.

\subsubsection{Classification Systems}

One of the most commonly employed methods for analysing multiple aircraft accidents is the 'Human Error Analysis and Classification System' (HFACS) which incorporates the human error work of Reason into different levels from the organisational down to the pilot $[6,21]$. This method has had particularly large use in the analysis of accidents, e.g. in China, revealing a need for safety improvements at the organisational and supervisory level to equip pilots with the resources and ability to perform their task in a safer manner $[10,22,23]$. The HFACS method provides a good global view of focus areas for the reduction of human error but it does not provide much insight into the errors within the process and their interactions.

\subsubsection{Network Modelling Approaches}

Bayesian Belief Networks (BBNs) are often used to develop models which quantify the probabilities of accident outcomes [24-27]. A recently developed 'Causal Model for Air Transport Safety' (CATS) integrates BBNs with event sequence diagrams and fault trees in a complex linear model [25]. This model is particularly complex and has a reliance on the values of the probability assigned to each outcome. The selection of these probability values is a point of interest as aviation safety is high in comparison to other transportation areas and accident occurrences are low, leading to a scarcity of data $[25,28]$. Models which employ BBNs are therefore limited by the quality of the available data and the expertise of their experts [28].

Network based methods allow for the analysis of aviation accidents in a non-linear fashion which can provide a better understanding of the interactions of different influences. The Event Analysis of Systemic Teamwork (EAST) methodology is one such network-based method which focuses on three major event areas: task, social and information, and the interaction of the three [29]. This model highlights the importance of pilot situational awareness, a factor known to contribute to accidents and an area for improvement in piloting system design [11, 29, 30]. Error detection strategies [31] and error management training are also proposed means to reduce pilot error by improving situational awareness and attitudinal and team factors [32]. The hardware design of the flight deck controls and instruments has been criticised as being overly oriented towards optimising physical ergonomics, and neglecting the cognitive ergonomics [33]. Thus design-induced errors [34] are another compounding factor contributing to situational awareness.

\subsubsection{Cognitive Processes and Sociotechnical Interactions}

Workload and cognitive loading is a known effect in human error generally, and flight and air traffic control are no exception [35-37]. Workload has also been modelled with BBNs [38]. There is also evidence that the usually assumed causality can be inverted: errors have been found to contribute to further workload in the flight situation [39].

Clearly human error has a cognitive basis. This was recognised early in the development of the field $[4,6,8,9$, $40,41]$. However the attribution, which is commonly made in the aviation industry, into slips, lapses, and mistakes, tends to obscure the deeper cognitive mechanisms. Attempts to better understand those have focussed on the cognition involved in the individual agent (though the term agent is more common in the psychology perspectives than in the engineering safety literature), and the breakdown of that cognition and memory [42]. Since much thought occurs in subconscious ways that are not explicit to the agent, this is a challenging area and understanding of the causality is limited. In these more complex situations, agents necessarily apply dynamic cognitive strategies for problem-solving [36, 43]. There is also the issue of shared (or distributed) cognition in teams [44], for which further factors (communication, coordination, cooperation, trust, cohesion) contribute to breakdown [45]. Interactions between agents will not necessarily conform to rules and prescription [46], and even cross-checking, which is a team interaction, is not infallible. Complex interactions occur between teams which in the flight setting are known to be affected by delegated roles (e.g. captain $v s$ flight officer) [47, 48].

A current area highlighted for further research and improvement is the area of sociotechnical interactions. The study of sociotechnical interactions considers human agents, electronic control systems, and physical artefactual hardware as components in a complex dynamically interacting system. System failure can occur due to the interactions, even if all the components on their own are functional. As there is degree of autonomy in most aircraft, the pilot's ability to interact effectively with the system without losing too much control or situational awareness is extremely important so that in an emergency event the pilot is still able to effectively take manual control of the aircraft $[11,15,49]$ or transition from one level of control (autopilot) to another (manual) [37], with incomplete information [46], or mode confusion [50] (dissonance between the mental model of the operator 
and the actual state of the technical system). The sociotechnical interactions on the flight desk are still not fully understood, particularly with respect to how they are affected by cultural influences [15], the representations of the hardware state to the pilot [46], and how the pilot builds mental awareness of the environment [51].

\subsubsection{Gaps in the Literature}

As the above literature shows, there is a need to better understand the causes of human-error in the context of the situational variables at the time. It is not sufficient to consider human-error as an independent random variable. Complex situations [52] are not readily solved by standard approaches, and in this regard the general safety engineering approaches may be too deterministic and simplistic in their assumed failure sequences. Traditional approaches based on defined failure probabilities, simplistic models of causation, linear sequences of events (Swiss cheese models), and treatments dependent on rules \& procedures, are insufficient for complex sociotechnical systems [43]. There is a need for methods that examine the system as a whole, rather than piecemeal treatment of the structural components [53]. It is entirely possible that partitioning failure into 'human' error, among other types, is entirely the wrong approach [40]. Perhaps we should instead be looking at how to model unintended system end-states. This is an opportunity for system-oriented approaches that treat the functional behaviour of the sociotechnical system as an integrated whole [53], though the difficulty has been finding a suitable representation.

\section{PURPOSE AND METHOD}

The purpose of this paper was to explore the intersection of human-error and production-process, from the systems engineering perspective. By production-process we refer to the set of actions necessary to move a system from one state to a desired new state. In this systems engineering perspective, a process is a set of mechanisms for taking inputs and converting them to the desired outputs, under certain controls and constraints. Landing an aircraft, which is the specific case under examination, is just such a process, though it is uncommon to see it this way. It involves taking an input system, an aircraft at certain altitude \& speed etc., and through a specific set of procedures and mechanics, convert it to a static intact aircraft on the apron and with its passengers safely off the craft. Once reframed like this, it becomes more apparent that it can be represented as a production engineering perspective, and human-error then explored in that way.

The overall production process of getting passengers from airport A to airport B may be broken into many phases, including maintenance, preparation of the aircraft, initial taxiing, take-off, level flight, manoeuvres, landing, terminal taxiing, etc. Some of these activities, such as maintenance, are not value-adding in a production sense, i.e. the passenger is not progressing from $\mathrm{A}$ to $\mathrm{B}$, but can still provide opportunity for error incursion with later accident consequences. These errors are comparable to what in the production situation would be called defects, hence concepts of quality and minimisation of waste (lean manufacturing). Modelling the whole operation as production process, and including all the errors, is beyond the present scope. Instead we had a more modest objective, which was to check whether the production-lens could be usefully applied to error in the aircraft situation. Consequently the analysis was limited to one phase only. This was to limit the complexity of interactions between multiple phases, and because the types of error are known to be different in the various phases. We were particularly interested in the dynamic interaction between operators and the technology, i.e. sociotechnical interaction, and thus selected one of the flight phases, as opposed to say maintenance where the issues are different. We selected landing as opposed to take-off, level flight, or other manoeuvres, as there tend to be more accidents in this phase, hence more data are available.

The method consists of three main activities. The first was to construct a system model of the landing process using a production-engineering method. The second was to create a classification scheme for human-error in the landing context. The third was to examine an on-line repository of aircraft crash reports, from which were extracted case-study data. These three activities were conducted in parallel, and informed each other in an iterative manner.

\subsection{Method for System-Modelling}

The modelling method is an application of systems engineering, specifically a deductive-inductive process. We developed this as a general method, and have successfully applied it to other situations $[54,55]$. We describe it as follows:

'It uses a structured, deductive process to decompose the process being analysed into multiple sub-activities (functions) and for each deduce the initiating events, the controls that determine the extent of the outputs, the inputs required, the process mechanisms that were presumed to support the action, and the outputs. The model was then inductively reconciled with elements of the existing body of knowledge on this topic, and successively refined. The end result is a graphical model that describes the relationships between variables, thereby providing a synthesis of what is known and surmised about the topic. The model is expressed as a series of flowcharts using the integration definition zero (IDEF0) notation $[56,57]$. With IDEF0 the object types are inputs, controls, outputs, and mechanisms (ICOM) and are distinguished by placement relative to the box, with inputs always entering on the left, controls above, outputs on the right, and mechanisms below. The box itself describes a function (or activity), and the arc (line arrow) describes an object. The arrows represent the conveyance of objects to activities and not sequence of activities. Consequently an activity may begin autonomously when its required inputs are available and its constraints permit. Importantly, multiple activity boxes can therefore be simultaneously active (concurrent/parallel), and sequenced activities (series) can also be readily modelled' [54, 55]. 
Table 1. Case studies used in the analysis.

\begin{tabular}{|c|c|c|c|}
\hline 1 & RusAir & Rusair T134 at Petrozavodsk on Jun 20th 2011 & {$[58]$} \\
\hline 3 & Georgia Airways & Georgian Airways CRJ1 at Kinshasa on Apr 4th 2011 & {$[60]$} \\
\hline 4 & Polish Air Force & Polish Air Force T154 at Smolensk on Apr 10th 2010 & {$[61]$} \\
\hline 6 & Fedex MD11 & Fedex MD11 at Tokyo on Mar 23rd 2009 & {$[63]$} \\
\hline 7 & Afriqiyah A332 & Afriqiyah A332 at Tripoli on May 12th 2010 & {$[64]$} \\
\hline 8 & Air India Express & Air India Express B738 at Mangalore on May 22nd 2010 & {$[65]$} \\
\hline 9 & Agni Air & Agni D228 at Jomsom on May 14th 2012 & {$[66]$} \\
\hline 13 & Conviasa & Conviasa AT42 near Puerto Ordaz on Sep 13th 2010 & {$[70]$} \\
\hline 14 & Colgan DH8D & Colgan DH8D at Buffalo on Feb 12th 2009 & {$[71]$} \\
\hline 15 & Aviastar Mandiri & Aviastar Mandiri B463 at Wamena on Apr 9th 2009 & {$[72]$} \\
\hline
\end{tabular}

\subsection{Case Studies}

The Aviation Herald was used to extract case-study data. The case studies were selected based on outcome severity, so that only crashes (accidents with the potential to cause fatalities of all on board) were analysed. The case studies are listed in Table $\mathbf{1}$.

For each case study we processed the reports and categorised the errors according to when in the process they occurred. The classification system is shown in the results below, and includes engineering failures, human-error, and weather conditions. Our interest was primarily in the humanerror conditions, and thus this section has more detail than the others. A total of fifteen cases were processed in this way.

\section{RESULTS}

\subsection{System Model of the Landing Process}

The resulting flowchart representation of the landing process modelled using the IDEF0 notation is shown in Fig. (1). The flowchart shows the deconstruction of the landing process into the major activities which take place, inclusive of some uncommon yet possible activities such as land and hold short operations (LAHSO). Because of this not all activities are completed during a single successful landing approach. The model also has some recursive elements where the landing approach can be carried out more than once following a go-around or similar. Each action has an accompanying code and each action input a descriptor. The figure gives the flowchart from which a safe landing process culminating in the safe arrival of the aircraft at the terminal, can be derived. The crash activity is also included in the diagram. A high number of inputs can lead to a crash outcome as it is possible for a crash to occur during any stage of the landing approach. Not all of these are shown in Fig. (1) for this system model so that the model can preserve as much simplicity as possible.

\subsection{Classification Scheme for Landing Errors}

The factors influential to a landing approach were divided into three main classes - human factors, technical failures and weather stimulus. A fourth category was used to classify the severity of the crash outcome. The classification system was developed in conjunction with the analysis of the cases studies and improved and refined iteratively. We developed this classification system by subjectively extracting factors from the crash data, as opposed to automatically following the slip/lapse/mistake/violation paradigm, since our priority was to build a model that was coherent with the data rather than with conventional constructs. Nonetheless there are recognisable commonalities that emerge.

The classification scheme is based on the explicit behavioural events evident in the failure reports. We take an evidence-based approach, and avoid inferring anything that is not present in the reports. Consequently the classification scheme is more likely to be a fault tree, and other implicit behavioural-shaping factors are not represented here. Nor there is any attempt to interpret the data according to some preferred theory of error causality. This does mean that the scheme only captures the surface actions, as opposed to the reasons beneath those. We are comfortable with this approach because the various protagonists in the flight situation respond to each other's explicit behaviours (including lack thereof), and the tacit behavioural-shaping factors are hidden from each other.

All human factors are described from the point of view of the person who is pilot-flying, the person of interest in the analysis undertaken. As the human factors were the focus of 


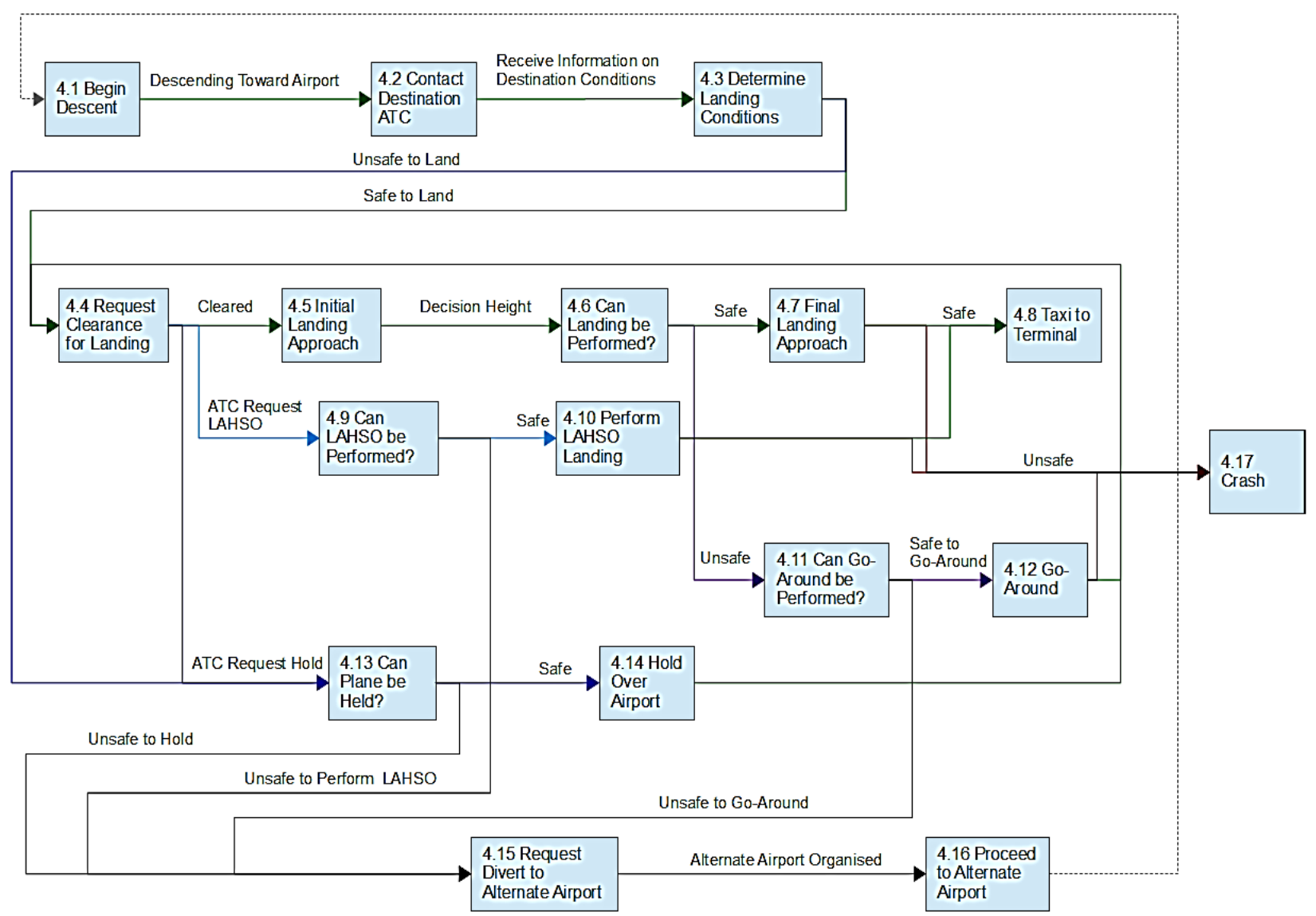

Fig. (1). System model of a safe landing process, and the crash outcome, represented in IDEF0 notation.

this model the human factor category was split into four subcategories: pilot flying actions, procedural failure, decision failure/misjudgement, and team dynamic influences. The first subcategory, pilot flying inability, describes influences which are inherent in the pilot's ability to fly at the time of the accident and can most often be considered as the responsibility of the airline who have a duty to ensure its pilots are competent. The second subcategory, procedural failure, is a failure by the pilot to correctly follow a well-defined or semi-automatic process. Subcategory three, decision failure/misjudgement, describes failures of the individual to interpret sometimes ambiguous or conflicting data to provide a necessary response. The final subcategory, team dynamic influence, defines external influences from other team members which add increased complexity to the pilot's tasks.

Table 2 provides descriptions and codes for the categories and subcategories used for influence classification. Quantities are given in the right hand column of the table denoting the number of cases out of the fifteen studied in which each influence type was a prevalent factor. Influences of each type, particularly human factors, may have occurred multiple times during a single landing process but for the purpose of this overview they are only counted once per case study.
No special claim is made for this classification scheme. It is simply an evidence-based summary of the agency apparent in the accident reports. A more comprehensive scheme could be developed, underpinned by an error theory of choice. However that is left for future work, since our present purpose is to explore the feasibility of the production perspective, for which this simple scheme is a sufficient starting point.

\subsection{Case Studies}

The case-studies were evaluated and the error codes extracted. These incidences are shown in Table 2 above. They are also mapped onto the process diagram at the activity level as opposed to the case level, as shown in the figures below (Fig. 2).

Fig. (2) highlights the landing process taken by the flight of the first case study with the error codes experienced at each activity stage mapped onto the flowchart. Activities not undertaken during the landing process are rendered in light grey as opposed to blue to distinguish them. In the top right corner error codes for environmental influences, those influences which affect the entire landing process, are listed.

Fig. (3) gives the flowchart with all fifteen cases studies mapped onto it. The thickness of the arrows lines are used to 
Table 2. Classification table and incidences from case studies.

\begin{tabular}{|c|c|c|}
\hline \multicolumn{2}{|r|}{ H: Human Factors } & \multirow[t]{2}{*}{ QTY } \\
\hline H1 & Pilot Flying Inability & \\
\hline H1.1 & Lethargy & 2 \\
\hline $\mathrm{H} 1.2$ & Inadequate Training & 4 \\
\hline H2 & Procedural Failure & \\
\hline $\mathrm{H} 2.1$ & Checkpoint not Acknowledged & 2 \\
\hline $\mathrm{H} 2.2$ & Improper Planning or Preparation & 6 \\
\hline $\mathrm{H} 2.3$ & Incorrect Procedure Employed & 5 \\
\hline $\mathrm{H} 2.4$ & Bad Approach Profile & 6 \\
\hline H3 & Decision Failure/Misjudgement/Disregard & \\
\hline H3.1 & Advice Disregarded & 5 \\
\hline $\mathrm{H} 3.2$ & Warning Signal Disregarded & 8 \\
\hline $\mathrm{H} 3.3$ & Improper Action Taken to Improve Approach Profile & 5 \\
\hline $\mathrm{H} 3.4$ & Decision Delay or Insufficient Action & 5 \\
\hline H4 & Team Dynamic Influence & \\
\hline H4.1 & Bad Team Dynamics or Communication & 5 \\
\hline $\mathrm{H} 4.2$ & False Information or Information Withheld & 2 \\
\hline $\mathrm{H} 4.3$ & Team Disruption or Confusion & 3 \\
\hline $\mathrm{H} 4.4$ & Conflict of Interests & 1 \\
\hline H5 & Cognitive effects & \\
\hline H5.1 & Excessive workload & \\
\hline H5.2 & Incongruence and Conflicting task demands & \\
\hline \multicolumn{2}{|r|}{ T: Technical Failures } & \\
\hline T1 & Propulsion Failure & 1 \\
\hline $\mathbf{T 2}$ & Instrument Failure & 2 \\
\hline $\mathbf{T 3}$ & Landing Gear Failure & 1 \\
\hline T4 & Navigation System Failure & 1 \\
\hline $\mathbf{T 5}$ & Approach Lighting Failure & 1 \\
\hline \multicolumn{2}{|r|}{ W: Weather Stimulus } & \\
\hline W1 & Wind Shear & 2 \\
\hline $\mathbf{W} 2$ & Lightening Strike & 0 \\
\hline W3 & Fog/Low Visibility & 8 \\
\hline W4 & High Winds & 0 \\
\hline W5 & Heavy Rain & 2 \\
\hline W6 & Icing Conditions & 1 \\
\hline \multicolumn{2}{|r|}{ X: Outcome Severity } & \\
\hline $\mathbf{X 1}$ & Minimal Damage to Aircraft & 0 \\
\hline $\mathbf{X} 2$ & Significant Damage to Aircraft & 0 \\
\hline $\mathbf{X} 3$ & Some Fatalities & 8 \\
\hline $\mathrm{X} 4$ & Full Fatalities & 7 \\
\hline
\end{tabular}

represent the number of cases which arrive at each action from the previous action. The number of cases which carry out each action is also denoted by the number shown in parentheses in the lower right corner of each action box. Actions which were not undertaken by any of the fifteen case studies are rendered in grey as before. For this aggregate flowchart, each error code has an associated occurrence number following it in parentheses. This occurrence number describes the number of cases, out of the fifteen cases studied, which had at least one influence of the error code type at that particular process action. When cases are considered individually there are often multiple errors of the same occurring at the same process action, however to note multiple errors of the same type on an aggregate flowchart would be misleading and it is more valuable to represent the cases in this way in order to derive more interesting conclusions.

The present dataset ( 15 cases) is intended only to validate the methodology, and does not have great statistical power. Nonetheless it is possible to extract some observations and insights.

\subsection{Integration and Interpretation}

Taking the process perspective is useful as it teases out where the human-error occurs in the process. The results show that landing crashes are primarily associated with poorvisibility WEATHER as the overall situational variable. The failure sequence itself originates primarily, and relatively consistently, in the process of INITIAL LANDING APPROACH (as opposed to later). The main contributors to failure are human error, specifically types $\mathrm{H} 2$ procedural failure and $\mathrm{H} 3$ decision failure/misjudgement.

First, this model shows that the $\mathrm{H} 2$ human procedural errors are prevalent throughout the process, but are the dominant error-stream at processes 4.1 to 4.4. In other words, the antecedents for accidents are occurring when pilots are initially engaging with the landing sequence of processes, which is well before the actual landing approach. Thus, at least in these cases, it is the initial decision-making which makes up the dominant type of human error. In particular, these pilots are not following established good practices, not initially nor later.

Obviously pilots do not willingly fly to their doom, and are generally well-trained in the procedures. So why are they ignoring the initial landing processes? We cannot answer that from within this study, but we can ask the questions: Are they over-confident and blasé? Or stressed and distracted? Cognitively over-burdened? Inexperienced or Inadequately trained?

Second, the model shows that $\mathrm{H} 3$ human decision errors are crowded at the 4.5 process (initial landing approach). (The $\mathrm{H} 2$ procedural errors are also continuing at this stage). These H3 errors are of the 'disregard' type. They are disregarding warning information and not deviating from their disastrous course of action. They display a persistence with a poor decision: having made the initial poor decision these pilots pass over subsequent opportunities to change their decision to a better one. For example, they are not using the go-round loop as much as they might, nor diverting to other airports. It would seem that these pilots are not open to 


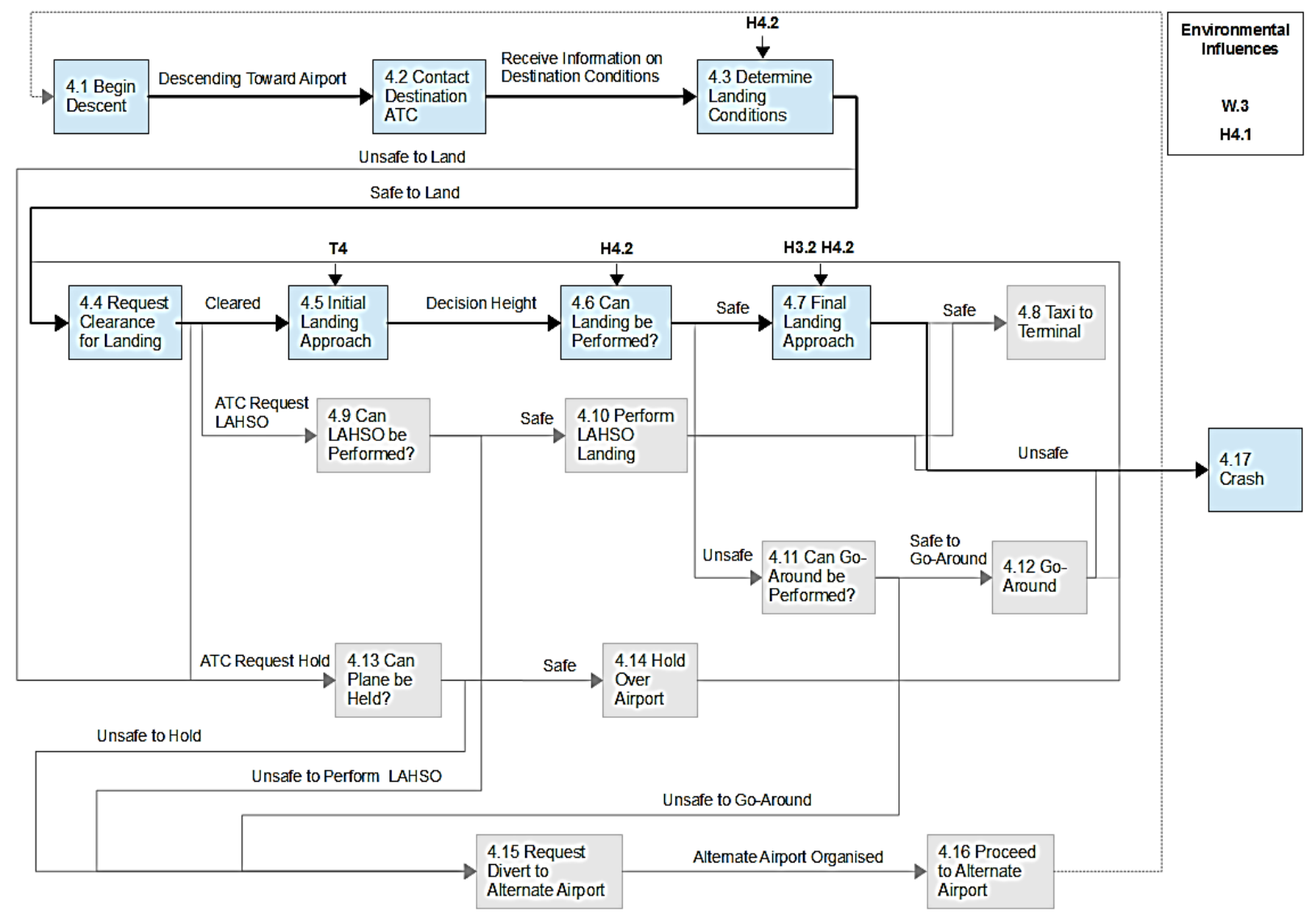

Fig. (2). Examination of a single case study (RusAir) showing the errors mapped onto the process diagram.

de-biasing themselves. It would appear they are disregarding disconfirmatory information that is not consistent with their mental model and its associated decisions, i.e. a confirmation bias. Is this a problem with a limited mental model of the aircraft-in-the-situation? Are they feeling subconscious pressure to land the aircraft immediately, and if so why?

It is also notable that the decisions that lead to accidents are being made under conditions of low visibility (W3 weather condition). This suggests there could be an interaction between decision-making and the external visualfield. What is it about low visibility, as opposed to other weather conditions, that uniquely makes pilots take chances, dispense with procedures, and persist with poor decisions?

Putting all this together, a tentative overall recommendation emerges: that better de-biasing processes may be needed in the cockpit, specifically at or immediately before initial landing approach (4.5), and especially under conditions of low visibility. Pilots need to recognise the process-stages and situations where it is wise to question their own decisions.

We therefore suggest it is useful to consider the phasing of human error relative to the process stages. As this model shows, there are different types of errors at different stages. Consequently the implication is that programmes to reduce error rates would be more effective were they to focus on the particular errors at particular stages, rather than simply treat human error as a lumped parameter.

\section{DISCUSSION}

\subsection{What has been Achieved?}

This paper makes several novel contributions. The first is the methodological contribution of demonstrating that a production-process approach can be used to define a system model of the landing process, in which human error can readily be included. This process-based style allows the analyst to determine when in the landing process the errors occur. Thus this methodology makes the progression (or time) dimension explicit in the human-error analysis, and thereby readily provides for the inclusion of time-dependent situational variables. Several novel propositions emerge from this line of thinking.

A second contribution is the provision of descriptive physical models for the analysis of aviation accidents during the landing process. Specific subcomponents to this model are a classification system for human errors in this context. Our analysis of the data suggest that in this situation there are four subcategories of human error: pilot flying inability, procedural failure, decision failure/misjudgement, and teamdynamic influences. We did not set out to prove or disprove the conventional construct of slip/lapse/mistake/violation, but nonetheless our results find against it. In hindsight it is apparent that Reason's model is focussed, we would say too strongly, around the premise of an individual human agent. In contrast we suggest that the interaction of multiple human 


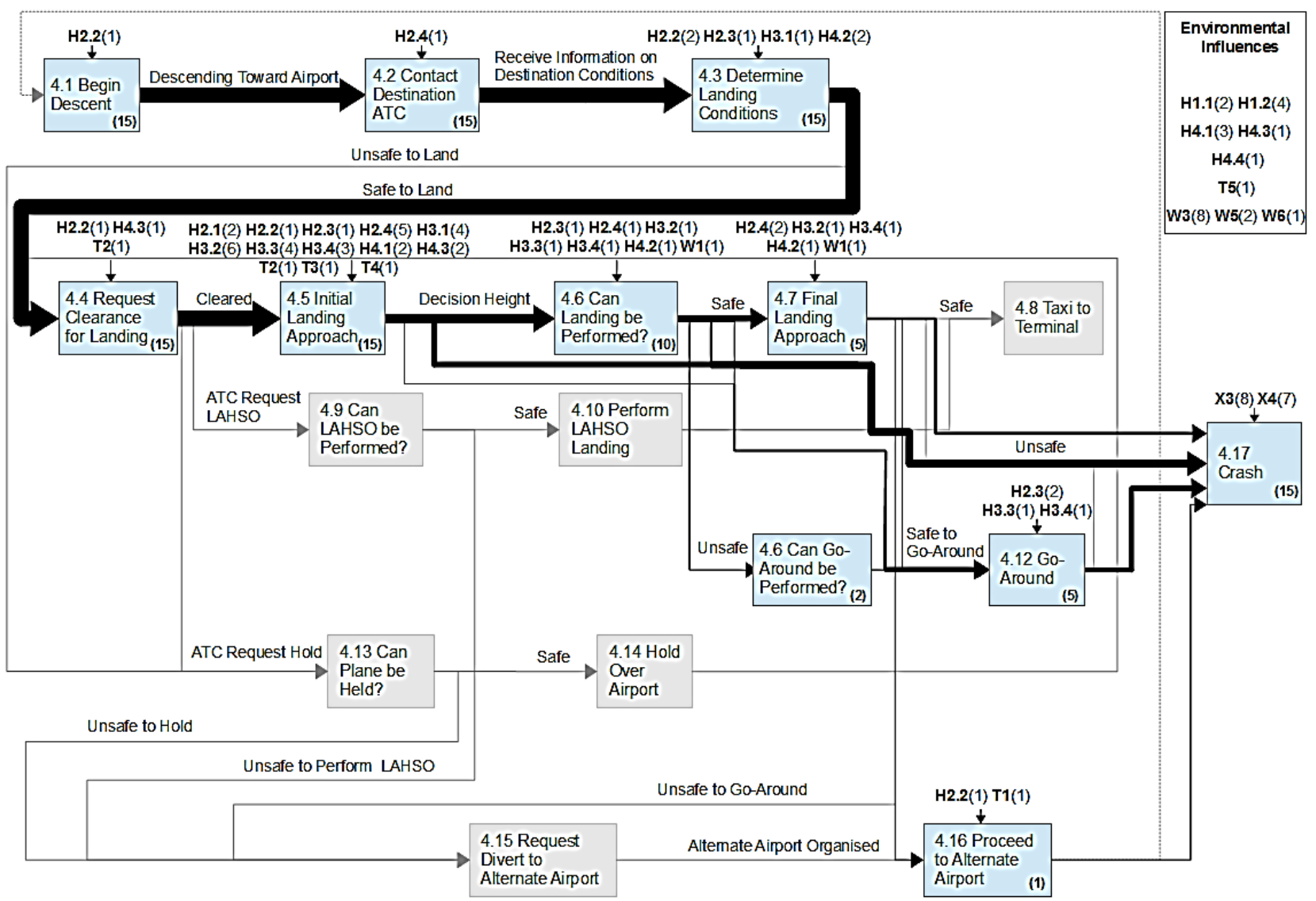

Fig. (3). Aggregation of multiple case-studies with error codes by subcategory.

agents (team-dynamics) and the interaction with the complex technical system (evident in decision failure) are as important as isolated consideration of the individual. It is the application of the production perspective that makes this contrast clearer: looking at the production processes that lead to these crashes, one cannot but see the importance of these other factors.

We have also provided a production model for the landing process. In addition we have shown that it is straightforward to use this to both aggregate the results from case studies, and extract single cases for scrutiny. The method offers a form of qualitative longitudinal analysis.

A third contribution is the determination, based on data, of the critical processes. This analysis method was particularly useful in determining the importance of the initial landing approach to the decision height at which the landing must either continue or be aborted. It is during this process that a large number of human error factors occur and following this process that subsequent actions tend to diverge. It is also at this process that technical failures may occur and the pilots' management of these during this critical phase of the landing process is therefore of high importance.

\subsection{The Production Lens}

Fundamental to this model is the thinking that human error is something to be expected, and therefore actively debiased against. Existing approaches to human error tend to give it a pejorative meaning, treating it as an unnatural, bad, or negligent behaviour that must be stamped out. We are not convinced that is the best way treat it. Specifically, we are concerned that framing human error as negligence immediately sets it up in conflict with the conscientiousness and need for achievement motivation that operators (pilots in this case) may naturally bring to their work, and thereby subconsciously invites operators to deny the possible agency of the effect in their own behaviour. We do not dismiss the severity of the consequences of human error in aviation, but we do feel that it is better to bring human error into the open, to mainstream it with the other processes that are happening at the time, and treat as any other production problem. To the way of thinking that we suggest, human error is one of many production factors the variability of which affects the quality of the outcomes. From a production perspective it may not be possible to eliminate these variables, but it should at least be possible to reduce their effect. Furthermore, the production perspective strongly suggests that the way to improve processes that are out of control is not by simply adding more output control, but rather involves working with the operators to understand where and why the variability occurs, and then find ways to reduce it.

The results show, in the specific cases under examination, that the persistence of initial mistakes can occur even in situations where operators are specifically trained, individually and as a group, to be alert to such behaviours. It suggests that training, knowledge, and team 
cross-checks are in themselves insufficient to break the failure causality in all cases. Many of the cases could have ended better if the protagonists had questioned their own comprehension. Early in the processes they adopted what were to be unsuitable mental models of how the craft was performing, e.g. how it was physically interacting with the external environment and how its control systems were interfacing to the pilots. It is apparent that complexity and remoteness of the technology contribute to the difficulty of diagnosing malfunction and comprehending the appropriate course of action, even for well-trained flight-crews working constructively. As the case of flight AF 447 craft F-GZCP (2009) showed, the flight-crew were unable to comprehend what was happening with the craft once the automated systems disconnected [73]. It is not certain that the development of more knowledge, through more training, will help this type of situation. The issue is cognitive processes, rather than knowledge per se. In all the examples studied here, the flight-crews did not appear to question the sufficiency of their cognitive constructs, and thus were unable to make a transition to a better understanding of how the system was behaving and where their personal agency should be applied. The need is therefore for a deeper mechanism to de-bias the cognition, especially the diagnostic and agency frameworks at the level of individual protagonists. That is not a novel finding as it is consistent with the literature, but it is support for the method.

\subsection{Limitations and Opportunities for Further Research}

We have already identified the limitation of the classification scheme (its focus on explicit surface behaviours rather than underpinning cognitive factors), and the poor statistical power of the limited case-base. There are additional limitations which are briefly identified below.

As this method for analysis requires such a deep analysis of each case in order to gain useful information it is therefore limited to cases for which such information is available. In our specific case we only had access to information that is publically available, and of the many cases reviewed only a relatively small proportion (those shown) had the necessary quality of data for inclusion. Nor were the full flight records and cockpit transcripts available for this analysis, so it was not possible to infer whether there may have been misinterpretation, information overload, workload, or other team behaviours, unless these were included in the accident report.

If more data could be gained by applying this analysis tool to further case studies, statistical analysis of the influences and process stages at which they occur could be carried out. By statistically analysing this data, further trends and relationships may be exposed which could in turn highlight areas for improvement within the aviation sector. Civil aviation agencies have the type of data required for this methodology and could be encouraged to apply the longitudinal type of analysis that the process perspective enables.

Also, our work was limited to the landing phase, and even then to crashes. There are many other situations that could be explored with this methodology, including other phases in the airtravel process, and less negative outcomes.
For example, is it possible to characterise best-practice outcomes in a similar way?

Another limitation, this time a deliberate one, is that the study does not attempt to attribute deeper causality to the actions of the protagonists. The reason for avoiding any deeper attribution of causality is that the risk was too high of having the work captured by one or other of the prevailing paradigms of human error, i.e. an attribution bias. Instead we wanted to see whether the production perspective could, starting from a clean slate, have anything meaningful and insightful to say about human error. The results shows that this is indeed the case. Nonetheless the development of a deeper theory of human error, complementary to the present more empirical outcome, is desirable as a future endeavour.

\section{CONCLUSION}

The purpose of this work was to investigate human error in aviation as a part of landing process. We have developed a novel process methodology for considering how technical systems, situational variables, external factors, and human error all evolve over time in a process. We have demonstrated the applicability of the method by application to a small dataset.

Taking the production perspective permits a novel process-methodology to be developed, in which human error is treated as a constraint on the processes. In parallel, a new categorisation of human errors is derived for the situation under examination, this being aircraft landing. The result in a process model of the landing activities, represented in IDEF0 flowchart notation, and explicitly identifying what human errors occur where. The analysis is therefore down to the level of individual processes, as opposed to looking at landing as a single event. The method was applied to several case studies of real accidents. These could be examined individually, or more interestingly, examined collectively for patterns. The results show that the initial landing approach is critical and often the point of error initiation.

If the model is correct, then the implications are that the initial landing approach is critical and that pilots should be trained to be able to manage influences, distractions, complications, and errors at this stage of flight in particular. The failure causality, for the accidents examined, was the lack of attention to establish procedure at the very start of descent, followed by persistent disregard of disconfirmatory evidence at the initial landing approach, under conditions of poor visibility.

\section{CONTRIBUTION STATEMENT}

KD collected the data, built the model, and investigated the literature. DP provided the initial idea, oversight, the systems methodology, and the production perspective. All authors contributed to writing the paper.

\section{CONFLICT OF INTEREST}

The authors declare no conflict of interest regarding the publication of this paper. The research was conducted without commercial or financial benefit from a third party. There was no third-party influence in the work: its approach, 
interpretation of data, writing, or submission decisions. There were no external funding bodies involved in this work.

\section{ACKNOWLEDGEMENTS}

The authors acknowledge the work done by the Aviation Herald (http://avherald.com) in aggregating and disseminating reports on diverse aircraft incidents.

\section{REFERENCES}

[1] AS/NZS 4360. Risk management. Australian/New Zealand Standard, Standards Australia, GPO Box 5420, Sydney, NSW 2001, 2004.

[2] AS/NZS HB436. Risk management guidelines. Australian/New Zealand Standard, Standards Australia, GPO Box 5420, Sydney, NSW 2001, 2004

[3] ISO 31000. Risk management -- Principles and guidelines International Organization for Standardization, 2009 Document No.: ISO 31000

[4] Swain AD. Human reliability analysis: needs, status trends and limitations. Reliab Eng Syst Saf 1990; 29: 301-13.

[5] Siu N. Risk assessment for dynamic systems: an overview. Reliab Eng Syst Saf 1994; 43(1): 43-73.

[6] Reason J. Human Error. Cambridge University Press: Cambridge 1990.

[7] Leplat J, Rasmussen J. Analysis of human errors in industrial incidents and accidents for improvement of work safety. Acc Anal Prevent 1984; 16(2): 77-88

[8] Rasmussen J. A taxonomy for describing human malfunction in industrial installations. J Occup Acc 1982; 4(2-4): 311-33.

[9] Rasmussen J. Human error mechanisms in complex work environments. Reliab Eng Syst Saf 1988; 22(1-4): 155-67.

[10] Ma R, Yuan X-G. Human error and system safety: Case study of commercial aviation accidents in Mainland China. $2^{\text {nd }}$ IEEE International Conference on Emergency Management and Management Sciences, ICEMMS; 2011 Aug 8-10; Beijing, China: IEEE Computer Society 2011

[11] Jin H, Wang L. Applying situation awareness to human-machine interface design of aviation. $2^{\text {nd }}$ International Symposium on Knowledge Acquisition and Modeling, KAM; 2009 Nov 30-Dec 1; Wuhan, China: IEEE Computer Society 2009.

[12] Al-Zubaidy SN. Proposal for modeling the piloting system. $2^{\text {nd }}$ Asia International Conference on Modeling \& Simulation; 2008 May 13-15; Piscataway, NJ, USA: IEEE 2008.

[13] McFadden KL. Comparing pilot-error accident rates of male and female airline pilots. Omega 1996; 24(4): 443-50.

[14] Bazargan M, Guzhva VS. Impact of gender, age and experience of pilots on general aviation accidents. Acc Anal Prevent 2011; 43(3): 962-70.

[15] Strauch B. Can cultural differences lead to accidents? Team cultural differences and sociotechnical system operations. Human Factors 2010; 52(2): 246-63.

[16] Merritt AC, Helmreich RL. Human factors on the flight deck - The influence of national culture. J Cross-Cult Psychol 1996; 27(1): 524

[17] Feng X, Li J. Analyzing pilot-related accidents and incidents by data mining. International Conference on Computer Application and System Modeling; 2010 Oct 22-24; Shanxi, Taiyuan, China: IEEE Computer Society 2010.

[18] Helmreich RL, Merritt AC, Wilhelm JA. The evolution of crew resource management training in commercial aviation. Int J Aviat Psychol 1999; 9(1): 19-32.

[19] Helmreich RL, Merritt AC. Safety and error management: The role of crew resource management. Hayward BJ, Lowe AR, Eds. Aldershot Ashgate Publishing Ltd 2000; pp. 107-19.

[20] Sherman PJ, Helmreich RL, Merritt AC. National culture and flight deck automation: Results of a multination survey. Int $\mathrm{J}$ Aviat Psychol 1997; 7(4): 311-29.

[21] Wiegmann DA, Shappell SA. A human error approach to aviation accident analysis: The human factors analysis and classification system. Burlington, VT Ashgate 2003.

[22] Li W-C, Harris D, Yu C-S. Routes to failure: Analysis of 41 civil aviation accidents from the Republic of China using the human factors analysis and classification system. Acc Anal Prevent 2008; 40(2): 426-34.

[23] Ting L-Y, Dai D-M. The identification of human errors leading to accidents for improving aviation safety. $14^{\text {th }}$ IEEE International Intelligent Transportation Systems Conference, ITSC; 2011 Oct 57; Washington, DC, United states: Institute of Electrical and Electronics Engineers Inc 2011.

[24] Ale BJM, Bellamy LJ, Cooke RM, et al. Towards a causal mode for air transport safety-an ongoing research project. Safety Sci 2006; 44(8): 657-73.

[25] Ale BJM, Bellamy LJ, van der Boom R, et al. Further development of a causal model for air transport safety (CATS): Building the mathematical heart. Reliab Engd Syst Saf 2009; 94(9): 1433-41.

[26] Oztekin AE, Luxhoj JT. A case-based reasoning (CBR) approach for representing and indexing aviation accidents. $9^{\text {th }}$ World MultiConference on Systemics, Cybernetics and Informatics, WMSCI; 2005 July 10-13; Orlando, FL, United states: International Social Science Council (ISSC) 2005

[27] Oztekin AE, Luxhj JT. An inductive reasoning approach for building system safety risk models of aviation accidents. J Risk Res 2010; 13(4): 479-99.

[28] Brooker P. Experts, bayesian belief networks, rare events and aviation risk estimates. Saf Sci 2011; 49(8-9): 1142-55.

[29] Griffin TGC, Young MS, Stanton NA. Investigating accident causation through information network modeling. Ergonomics 2010; 53(2): 198-210.

[30] Sawaragi T, Murasawa K. Simulating behaviors of human situation awareness under high workloads. Art Intell Eng 2001; 15(4): 36581.

[31] Onken R, Walsdorf A. Assistant systems for aircraft guidance: Cognitive man-machine cooperation. Aerospace Sci Technol 2001; 5(8): 511-20.

[32] Kontogiannis T, Malakis S. A proactive approach to human error detection and identification in aviation and air traffic control. Safety Science 2009; 47(5): 693-706.

[33] Harris D. Human factors for flight deck certification: Issues in compliance with the new European aviation safety agency certification specification 25.1302. J Aeronautic Astronautics Aviation Ser A 2010; 42(1): 11-20.

[34] Stanton N-A, Harris D, Salmon P-M, et al. Predicting designinduced error in the cockpit. J Aeronautics Astronautics Aviation Ser A 2010; 42(1): 1-10.

[35] Svensson E, Angelborg-Thanderz M, Sjoberg L, Olsson S Information complexity - Mental workload and performance in combat aircraft. Ergonomics 1997; 40(3): 362-80.

[36] Desmond PA, Hoyes TW. Workload variation, intrinsic risk and utility in a simulated air traffic control task: Evidence for compensatory effects. Safety Sci 1996; 22(1-3): 87-101.

[37] Hainley Jr CJ, Duda KR, Oman CM, Natapoff A. Pilot performance, workload, and situation awareness during lunar landing mode transitions. J Spacecraft Rockets 2013; 50(4): 793801.

[38] Gregoriades A, Sutcliffe A. Workload prediction for improved design and reliability of complex systems. Reliab Eng Syst Saf 2008; 93(4): 530-49.

[39] Hart SG, Bortolussi MR. Pilot errors as a source of workload. Hum Fact 1984; 26(5): 545-56.

[40] Rasmussen J. Human error and the problem of causality in analysis of accidents. Philos Trans R Soc Lond Ser B-Biol Sci 1990; 327(1241): 449-62

[41] Kantowitz BH, Fujita Y. Cognitive theory, identifiability and human reliability analysis (HRA). Reliab Eng Syst Saf 1990; 29: 317-28

[42] Shorrock ST. Errors of memory in air traffic control. Saf Sci 2005; 43(8): 571-88.

[43] Carvalho PVRd, Gomes JO, Huber GJ, Vidal MC. Normal people working in normal organizations with normal equipment: System safety and cognition in a mid-air collision. Appl Ergon 2009; 40(3): 325-40.

[44] Inoue S, Furuta K, Nakata K, et al. Cognitive process modelling of controllers in en route air traffic control. Ergonomics 2012; 55(4): 450-64.

[45] Wilson KA, Salas E, Priest HA, Andrews D. Errors in the heat of battle: Taking a closer look at shared cognition breakdowns through teamwork. Human Factors 2007; 49(2): 243-56. 
[46] Henriqson E, van Winsen R, Saurin TA, Dekker SWA. How a cockpit calculates its speeds and why errors while doing this are so hard to detect. Cognit Technol Work 2011; 13(4): 217-31.

[47] Orasanu J, Fischer U, McDonnell LK, et al. How do flight crews detect and prevent errors? Findings from a flight simulation study. Proc Hum Fact Ergon Soc 1998; 1: 191-5.

[48] Orlady HW, Orlady LM. Human factors in multi-crew flight operations. Aeronaut J 2002; 106(1060): 321-4.

[49] Sawaragi T, Horiguchi Y, Hina A. Safety analysis of systemic accidents triggered by performance deviation. SICE-ICASE International Joint Conference; 2006 Oct 18-21; Busan, Korea, Republic of: Institute of Electrical and Electronic Engineering Computer Society 2006.

[50] Bredereke J, Lankenau A. Safety-relevant mode confusions Modelling and reducing them. Reliab Eng Syst Saf 2005; 88(3): $229-45$.

[51] Chouraqui E, Doniat C. The s-ethos system: A methodology for systematic flight analysis centered on human factors. Appl Artif Intell 2003; 17(7): 583-629.

[52] Rasmussen J. The role of error in organizing behaviour. Qual Saf Health Care 2003; 12(5): 377-83.

[53] Rasmussen J. Risk management in a dynamic society: A modelling problem. Saf Sci 1997; 27(2-3): 183-213.

[54] Lawry K, Pons DJ. Integrative Approach to the Plant Commissioning Process. J Indust Eng 2013; 2013(572072): 1-12.

[55] Pons DJ. Ventures of co-ordinated effort. Int J Project Organ Manag 2012; 4(3): 231-55.

[56] FIPS. Integration Definition for Function Modeling (IDEF0): Federal Information Processing Standards Publications, National Institute of Standards and Technology 1993 [Accessed: 12 Aug 2003]. Available from: http://www.itl.nist.gov/fipspubs/idef02.doc

[57] KBSI. IDEF0 Overview 2000 [Accessed: 12 Aug 2003]. Available from: http://www.idef.com/idef0.html

[58] Aviation Herald. RusAir T1342011 [Accessed: 7-12-2012]. Available from: http://avherald.com $/ \mathrm{h}$ ?article $=43 \mathrm{e} 7 \mathrm{c} 1 \mathrm{~b} 7 \&$ opt $=0$

[59] Aviation Herald. Henan Airlines E1902010 [Accessed: 7-12-2012]. Available from: http://avherald.com/h?article $=43 \mathrm{e} 7 \mathrm{c} 1 \mathrm{~b} 7 \&$ opt $=0$

[60] Aviation Herald. Georgia Airways CRJ12011 [Accessed: 7-122012]. Available from: http://avherald.com $/ \mathrm{h}$ ? article $=43 \mathrm{a} 6 \mathrm{f8} 04 \&$ opt $=0$
[61] Aviation Herald. Polish Air Force T1542010 [Accessed: 7-122012]. Available from: http://avherald.com $/ \mathrm{h}$ ?article $=429 \mathrm{ec} 5 \mathrm{fa} / 0$ 034\&opt $=0$

[62] Aviation Herald. Hewa Bora B7212011 [Accessed: 7-12-2012] Available from: http://avherald.com/h?article $=43 \mathrm{f} 62982 / 0000 \&$ $\mathrm{opt}=0$

[63] Aviation Herald. Fedex MD112009 [Accessed: 7-12-2012]. Available from: http://avherald.com/h?article=416e7619/0015\&opt $=0$

[64] Aviation Herald. Afriqiyah A3322010 [Accessed: 7-12-2012]. Available from: $\mathrm{http}: / /$ avherald.com $/ \mathrm{h}$ ?article $=42 \mathrm{~b} 63 \mathrm{~b} 20 / 0000 \&$ op $\mathrm{t}=0$

[65] Aviation Herald. Air India Express B7382010 [Accessed: 7-122012]. Available from: http://avherald.com/h?article $=42 \mathrm{bd} 5 \mathrm{e} 46 / 00$ $02 \&$ opt $=0$

[66] Aviation Herald. Agni Air D2282012 [Accessed: 7-12-2012]. Available from: http://avherald.com $/ \mathrm{h}$ ?article $=44 \mathrm{f} 862 \mathrm{~b} 7 \& \mathrm{opt}=0$

[67] Aviation Herald. Merapati MA602011 [Accessed: 7-12-2012] Available from: http://avherald.com/h?article $=43 \mathrm{c} 2 \mathrm{~b} 059 / 0002 \&$ op $\mathrm{t}=0$

[68] Aviation Herald. AirBlue A3212011 [Accessed: 7-12-2012]. Available from: http://avherald.com $/ \mathrm{h}$ ?article $=42 \mathrm{ee} 2 \mathrm{e} 58 / 0000 \& \mathrm{o}$ $\mathrm{pt}=0$

[69] Aviation Herald. Katekavia AN242010 [Accessed: 7-12-2012]. Available from: http://avherald.com/h?article $=42 \mathrm{f} 1 \mathrm{~b} 7 \mathrm{df} / 0000 \&$ opt $=0$

[70] Aviation Herald. Conviasa AT422010 [Accessed: 7-12-2012] Available from: http://avherald.com/h?article $=430 \mathrm{e} 1137 \& \mathrm{opt}=0$

[71] Aviation Herald. Colgan DH8D2009 [Accessed: 7-12-2012] Available from: http://avherald.com/h?article $=414 \mathrm{f} 3 \mathrm{dbd} / 0038 \& \mathrm{o}$ $\mathrm{pt}=0$

[72] Aviation Herald. Aviastar Mandiri B4632009 [Accessed: 7-122012]. Available from: http://avherald.com $/ \mathrm{h}$ ?article $=417 \mathrm{cbf} 69 / 00$ $01 \&$ opt $=0$

[73] BEA. Flight AF 447 on $1^{\text {st }}$ June 2009, A330-203, registered FGZCP. Safety Reports 2012. Available from: http://www.bea.aero/ en/enquetes/flig ht.af.447/flight.af.447.php

(C) Pons and Karla; Licensee Bentham Open.

This is an open access article licensed under the terms of the Creative Commons Attribution Non-Commercial License (http://creativecommons.org/licenses/bync/3.0/) which permits unrestricted, non-commercial use, distribution and reproduction in any medium, provided the work is properly cited. 